\title{
COMPLICATIONS AND REASONS FOR CONVERSION OF LAPAROSCOPIC CHOLECYSTECTOMY TO OPEN CHOLECYSTECTOMY- A RETROSPECTIVE ANALYSIS OF 400 PATIENTS AT THE TURN OF THE CENTURY
}

\author{
Vikas Gupta1 ${ }^{1}$ Vanilla Chopra², Naseer A. Wani ${ }^{3}$ \\ ${ }^{1}$ Assistant Surgeon, Department of Surgery, Jammu and Kashmir Health Services. \\ ${ }^{2}$ Assistant Professor, Department of Anaesthesia and Critical Care, Acharya Shri Chander College of Medical Sciences. \\ ${ }^{3}$ Ex. Professor, Department of Surgery, Sher-E-Kashmir Institute of Medical Sciences.
}

\section{ABSTRACT}

\section{BACKGROUND}

Laparoscopic cholecystectomy has become the standard treatment for symptomatic gall bladder disease. However, there is still a substantial proportion of patients in whom Laparoscopic cholecystectomy cannot be successfully performed, and for whom conversion to open surgery is required.

Aim- In the present study we studied the various reasons for conversion of laparoscopic cholecystectomy to open cholecystectomy and complications associated with this procedure in a tertiary care centre at the turn of the century. Setting and Design- It is a retrospective, randomised study conducted over a period of 8 years.

\section{MATERIALS AND METHODS}

400 patients who underwent laparoscopic cholecystectomy under general anaesthesia were analysed for the complications, which were graded on a severity scale of 1 to 4 where Grade 1 complications were deviation from the ideal postoperative course, non-life threatening with no lasting disability and Grade 4 were death due to complications. If the conversion to open cholecystectomy was done, the reasons for the same were also analysed.

Statistical Analysis Used- Data comparison was performed by Student's t-test (continuous variables) and chi-square test (categorical variables). A significant difference was assumed with p-value less than 0.05 .

\section{RESULTS}

Of the 400 patients who were subjected to laparoscopic cholecystectomy, 30 patients $(7.5 \%)$ required conversion to open surgery. The most common reason for conversion was inability to define anatomy of Calot's triangle in patients with inflamed, contracted gall bladder $(n=15)$, followed by dense adhesions $(n=13)$ and uncontrolled bleeding $(n=2)$. The overall complication rate computed in our study was $4.8 \%$. The rates of Grade 1, Grade 2a and Grade 2b complications were 2.3\%, $0.3 \%$ and 2.3\% respectively and there was no Grade 3 or Grade 4 complications.

\section{CONCLUSION}

Complications of laparoscopic cholecystectomy can be minimised by maintaining a low threshold for elective conversion to open cholecystectomy, as the patient's safety must remain a foremost concern.

\section{KEYWORDS}

Cholecystectomy, Laparoscopic Surgery, Complications.

HOW TO CITE THIS ARTICLE: Gupta V, Chopra V, Wani NA. Complications and reasons for conversion of laparoscopic cholecystectomy to open cholecystectomy- a retrospective analysis of 400 patients at the turn of the century. J. Evolution Med. Dent. Sci. 2017;6(23):1882-1885, DOI: 10.14260/Jemds/2017/413

\section{BACKGROUND}

Gall bladder disease continues to be one of the most common digestive disorders encountered by a physician in the developed countries. In 1882, Carl Langenbuch, a German surgeon performed the first successful cholecystectomy. In our country also, this disease is very common with sex distribution of female: male 3: 1 . Although surgical removal of the Gall Bladder (GB) has been the Gold Standard of treatment for cholelithiasis for more than 100 yrs., the introduction of new technology for minimally invasive

Financial or Other, Competing Interest: None.

Submission 25-02-2017, Peer Review 09-03-2017,

Acceptance 13-03-2017, Published 20-03-2017.

Corresponding Author:

Vanilla Chopra,

\#49, 1-A, Trikuta Nagar, Jammu.

E-mail: vanillachopra@yahoo.co.in

DOI: $10.14260 /$ jemds $/ 2017 / 413$

\section{(c) $(1)$}

surgery and specifically laparoscopic cholecystectomy has revolutionised our approach to a number of problems and caused a re-evaluation of clinical strategies.(1)

Laparoscopic Cholecystectomy (LC) is a minimally invasive procedure, thereby GB is removed using laparoscopic technique. Laparoscopic cholecystectomy originated in Europe with the first successful case being performed by Phillipe Mauret in Lyon in 1987.(2) Now it has become the Gold Standard therapy for symptomatic gall stone disease, particularly in elective setting. The advantages of LC over traditional Open Cholecystectomy (OC) in terms of limited postoperative pain, shorter hospitalisation, early resumption of activity, reduction in hospital costs and improved cosmoses have been readily apparent.(3) As the number of surgeons performing LC enlarges, a rigorous evaluation of the safety of LC is appropriate. In its early days, complications after LC including major bile duct injuries reached a high rate of $3 \% .(4)$ This is 10 times more when compared with conventional cholecystectomy. Some have 
attributed this to the learning curve of this new technique.(2) Some of these complications and several other factors can necessitate the conversion of LC to OC.(5) The conversion from LC to OC results in a significant change in outcome for the patient, because of the higher rate of postoperative complications and the longer hospital stay. Therefore, the aim of the current study therefore is to evaluate in a large heterogeneous population, the rate of conversion of LC to OC and complications associated with LC.

\section{MATERIALS AND METHODS}

We evaluated the medical records of patients with gallstone disease who underwent LC in the Surgery Department of Sher-E-Kashmir Institute of Medical Sciences, Soura, Srinagar, over a period of 8 years, i.e. from Jan 1996 to Jan 2004. This period was chosen, because in this period Institute had just started with this technique of LC and we wanted to analyse the outcome and problems encountered in initial stages of learning in a tertiary care centre. All the patients who underwent laparoscopic operation for symptomatic gall stone disease during this period were taken as a basis for our study and were evaluated with respect to age, concomitant disease, percentage of additional common bile duct exploration, duration of operation, grade of complications and conversion to open cholecystectomy. Thus, it was possible to analyse a total of 400 laparoscopic cholecystectomy patients. Patients who have undergone upper abdominal surgery previously or were too obese or patients having any other associated pathology like jaundice, malignancy, choledocholithiasis, cardiovascular or pulmonary disease, major bleeding disorders or patients who were pregnant were excluded from the study. The conversion rate to $\mathrm{OC}$, the underlying reasons and postoperative complications were recorded. Any patient requiring re-exploration and reasons for it were analysed. Results were evaluated classifying surgical complications on a severity scale graded 1 to 4 .

\section{Grade 1}

Deviation from the ideal postoperative course, non-life threatening with no lasting disability, eg. prolonged stay due to ileus, fever, wound infection, urinary tract infection, pulmonary infection and costochondritis.

\section{Grade 2a}

Potentially life-threatening, but without residual disability, e.g. cholangitis, retroperitoneal haematoma, subhepatic collection, pancreatitis.

\section{Grade $2 b$}

Potentially life-threatening, but without residual disability. Surgery is necessary to restore health, e.g. bile duct injury requiring laparotomy and T-tube insertion, CBD injury combined with duodenal perforation, retained stones, complete common duct transection, bile leak, bleeding, gastrointestinal injury and bladder injury.

\section{Grade 3}

Complications with residual disability including organ resection or persistence of life-threatening conditions, eg. uncontrolled bleeding or shock, laceration of aorta, hepatic artery or mesenteric vein, portal vein injury, perforated iliac artery or vein.

\section{Grade 4}

Death due to complications.

\section{Statistical Analysis}

Statistical analysis of the data was conducted. Data are presented as mean \pm standard deviation and proportions or percentage as appropriate. Data comparison was performed by Student's t-test (continuous variables) and chi-square test (categorical variables). A significant difference was assumed with p-value less than 0.05 . All analysis was performed using the Statistical Package for Social Science (SPSS for Windows Version 16.0, SPSS Inc., Chicago, IL).

\section{RESULTS}

Of 400 cases taken up for laparoscopic cholecystectomy, 30 were converted to open procedure giving a conversion rate of $7.5 \%$ and the most common cause for conversion was unclear anatomy in Calot's triangle followed by dense adhesions and bleeding (Table 1).

In our study, overall complication rate was $4.8 \%(n=19)$. Grade 1 complications occurred in $2.3 \%(n=9)$ of cases. Prolonged drainage of blood stained fluid through drain was observed in 4 cases, subumbilical port site infection developed in $0.5 \%(n=2)$ of cases and one patient each had prolonged paralytic ileus, respiratory tract infection and fever (Table 2). No case of urinary tract infection or costochondritis was reported.

Among Grade 2a complications, cholangitis was seen in $0.3 \%(\mathrm{n}=1)$ of cases. No case of retroperitoneal haematoma or subhepatic collection or pancreatitis was reported.

Among Grade 2b complications Bile Duct Injuries (BDI) was reported in $0.75 \%(n=3)$ of cases. Out of which one was Strassburg type A, which was managed by papillotomy and stent placement. Second was Strassburg type E1, which needed choledochojejunostomy and third was Strassburg type E3 in which hepaticojejunostomy was done. The other Grade $2 \mathrm{~b}$ complications observed in our study were bile leak and bleeding in $1 \%(n=4)$ and $0.5 \%(n=2)$ of cases respectively (Table 3 ). There was no case of retained stone, gastrointestinal or bladder injury due to trocar insertion. There was no case of Grade 3 and Grade 4 complications in our study. No pneumoperitoneum related complications like CO2 embolism, hypercarbia, respiratory acidosis, subcutaneous emphysema, pneumothorax or pneumomediastinum was observed in our study.

\begin{tabular}{|c|c|c|}
\hline Reason for Conversion & No. of Cases & \% within Group \\
\hline Unclear anatomy & 15 & $3.8 \%$ \\
\hline Dense adhesions & 13 & $3.3 \%$ \\
\hline Uncontrolled bleeding & 2 & $0.5 \%$ \\
\hline Total & $\mathbf{3 0}$ & $\mathbf{7 . 5 \%}$ \\
\hline
\end{tabular}

Table 1. Showing Distribution of Cases according to Reason for Conversion

\begin{tabular}{|c|c|}
\hline Grade 1 Complication & No. of Cases \\
\hline Prolonged drainage & $4(1 \%)$ \\
\hline Paralytic ileus & $1(0.3 \%)$ \\
\hline Wound infection & $2(0.5 \%)$ \\
\hline Respiratory tract infection & $1(0.25 \%)$ \\
\hline Fever & $1(0.25 \%)$ \\
\hline Total & $9(2.3 \%)$ \\
\hline Table 2. Showing Grade 1 Complications
\end{tabular}




\begin{tabular}{|c|c|}
\hline Grade 2b Complication & No. of Cases \\
\hline Bile duct injury & $3(0.75 \%)$ \\
\hline Bleeding & $2(0.5 \%)$ \\
\hline Bile leak & $4(1.0 \%)$ \\
\hline Total & $9(2.3 \%)$ \\
\hline Table 3. Showing Grade 2b Complications \\
\hline
\end{tabular}

\begin{tabular}{|c|c|}
\hline Authors & \% Conversion \\
\hline Cuschieri et al(6,7) & $3.6 \%$ \\
\hline Dubois et al( $(8)^{(9)}$ & $7.7 \%$ \\
\hline Rubio et al $(9)^{(6)}$ & $2.3 \%$ \\
\hline Voyles et al $^{(}$ & $5.0 \%$ \\
\hline Orlando et al $(10)^{(1)}$ & $6.9 \%$ \\
\hline Raza M et al $(11)$ & $2.9 \%$ \\
\hline Sakpal NV(12) & $4.9 \%$ \\
\hline Our Series & $7.5 \%$ \\
\hline \multicolumn{2}{|c|}{ Table 4. Showing Rate of Conversion in various } \\
Published Series
\end{tabular}

\section{DISCUSSION}

LC has become the popular and standard method for removing the gallbladder. Limited postoperative pain, shorter hospitalisation stay, early resumption of activity, reduction in hospital costs and improved cosmoses are the major advantages of this method.(13,14)

In our study, rate of conversion from LC to OC was $7.5 \%$. Out of 30 cases that need conversion, 15 (3.8\%) were converted to OC because of unclear anatomy and fibrosis in Calot's triangle. It was the most common cause of conversion. Second most common cause was dense adhesions caused by tissue inflammation in $3.3 \%(\mathrm{n}=13)$ cases, while $0.5 \%(\mathrm{n}=$ 2) cases had uncontrolled bleeding from aberrant vessels in gall bladder bed as reason for conversion. In all patients who had bleeding, the haemorrhage was controlled with thermocoagulation and/or suturing. There was no conversion because of trocar insertion, diaphragmatic injury, right hepatic duct injury, common bile duct calculi or retroperitoneal haematoma. Conversion from LC to OC is considered neither a failure nor a complication of laparoscopic operation, but an attempt to avoid serious complications by the surgeon who acted judiciously, reverting to a 'safe' 100-year-old established technique. It often represents wise surgical judgment and has the potential to limit morbidity. This study also shared the view: "one conversion more is better than one bile duct injury more." In addition to an understanding of conversion within the Institution, we decided to retrospectively review our series and to compare our results with those reported in the literature where $5 \%-10 \%$ conversion rate is very acceptable in unselected series (Table 4).

Sanabria et al in their study of 628 patients reported that unclear anatomy along with adhesions and intra-operative bleeding was reason for conversion in $66 \%$ and $8 \%$ of the cases respectively.(15) Peters J H et al observed that difficult dissection and bleeding was the reason for $55 \%$ and $12 \%$ of conversions respectively in their study. They concluded that age $>65$ yrs., male sex and patients with multiple attacks of biliary colic or a documented history of acute cholecystitis had a greater risk for conversion.(16) 2.9\% patients required conversion to OC in a study conducted by Raza $\mathrm{M}$ et al and found that the predictor factors for conversion were chronic calculous cholecystitis, previous upper abdomen surgeries and CBD injuries(11) and a $2 \%$ conversion rate is seen in the study conducted by Narwade $\mathrm{N}$ et al.(17) Sakpal NV et al found a conversion rate of $4.9 \%$. The most common reason for conversion in their study was adhesions and the majority of the patients had prior abdominal surgery. They added that males and patients more than 50 years old had a significantly higher likelihood of open conversion.(12)

Among the Grade 2b complications, Bile Duct Injuries (BDI) are one of the most dreaded complications of cholecystectomy and in our study there were 3 cases of BDI. First case presented on 8th postoperative day with pain right hypochondrium and $80-100 \mathrm{~mL}$ of collection in subhepatic space and right paracolic gutter on Ultrasonography (USG). Endoscopic Retrograde Cholangiopancreatography (ERCP) revealed a frank leakage at the level of cystic duct opening with mild narrowing of CBD (Strassburg Type A). Patient was managed with papillotomy and stent placement. Second case presented with pain upper abdomen radiating to whole of abdomen on 15th postoperative stay. USG revealed significant collection in peritoneal cavity. Exploratory laparotomy revealed the presence of approximately one litre of bile in peritoneal cavity with loss of about $1 \mathrm{~cm}$ anterior wall of CBD and intact posterior wall (Strassburg Type E1). Patient was managed with T-tube insertion in CBD. During followup period, T-tube cholangiogram revealed CBD stricture with two limbs of T-tube across the stricture. After failure of repeated attempts to pass the guide wire across the stricture during ERCP, patient was managed with laparotomy in which removal of T-tube followed by closure of choledochotomy was done. Third case presented on 10th postoperative day with pain and tenderness all over abdomen and USG showing moderate collection of free fluid in peritoneal cavity and pelvis. On exploratory laparotomy, a $1.5 \mathrm{~cm}$ rent was found in the anterior wall of CBD at the junction of cystic and common hepatic duct, which was managed with external drainage of bile duct with $\mathrm{T}$ tube. During followup period, T-tube cholangiogram revealed CBD Stricture for which again laparotomy was done, which revealed a $2 \mathrm{~cm}$ long stricture involving upper part of CBD, whole of common bile duct up to confluence of right and left hepatic duct (Strassburg Type E3). Hepaticojejunostomy was done in this patient. None of the patients has any residual morbidity.

Our study revealed the incidence of BDI to be $0.75 \%$. This is consistent with the various studies conducted in the past, which shows that contemporary rate of BDI varies from $0 \%$ to $4 \%$. In the various studies conducted by Salheim K et al,(18) Sawyers JL(6) and Daniel $\mathrm{J}^{(4)}$ bile duct injury rate was $1.1 \%$, $0.3 \%-0.5 \%$ and $0.58 \%$ respectively. Rate of BDI is 15 times more during the early part of one's career when surgeons start doing LC which has been called as "learning curve effect."(7) BDI during LC are best avoided by maintaining a low threshold for conversion to laparotomy in any case, during which the anatomy cannot be precisely identified and by proper training of surgeons thereby reducing the learning curve effect.

Other Grade 2b complication reported in our study was bile leak, which was reported in $1 \%(n=4)$ cases. All the patients with this complication underwent exploratory laparotomy revealing accessory cholecystohepatic duct in 1 patient, accessory duct draining into left hepatic duct in the second patient and slippage of clip from cystic duct as the cause of bile leak in rest of the 2 patients. Daniel J concluded 
bile leak to be the most frequent post-operative technical complication of laparoscopic cholecystectomy with a rate of $0.29 \%$.(4) Voyles et al(19) and Cushieri et al(20,10) reported an incidence of $0.20 \%$ and $0.17 \%$ respectively of bile leak in their studies on laparoscopic cholecystectomy.

The other Grade $2 \mathrm{~b}$ complication observed in our study was bleeding. It carries $0.5 \%(n=2)$ incidence in our study. One patient had bleeding from the GB bed, while the other patient bled from the superior epigastric artery. Both the patients were managed with exploratory laparotomy.

In our study, overall complication rate was $4.8 \%(\mathrm{n}=19)$ and mortality was $0 \%$. Jatzko G $\mathrm{R}^{(21)}$ Orlando et al(22) and Daniel J et al(4) reported an overall complication rate of $1.5 \%$, $8.6 \%$ and $2 \%$ respectively in their studies on laparoscopic cholecystectomy. Jatzko and others in their study have observed that the main detrimental factors relating to overall complications are open cholecystectomy for Grade 1 complication, old age and acute cholecystitis for Grade 2a complication and old age, acute cholecystitis and length of operation for Grade $2 \mathrm{~b}$ complications.(21) In their study on laparoscopic cholecystectomy Cusheri et al,(20,10) Orlando et al ${ }^{(22)}$ and Paulino Netto(9) reported mortality rate of $0.3 \%$ each, Deziel et al(22) of $0.04 \%$, while no mortality was reported by Rubio, Voyles et al, Flower et al and Dubois F. $(8,23,24)$

In the end, we might assume that introduction of LC, a new surgical method for treatment of patients with cholelithiasis was adopted due to its great advantages for the patients and hence can be defined as the 'New Gold Standard' for their treatment. A number of problems still under discussion as well as the negative views of the supporters of conventional methods should not discourage us to continue our efforts and research in this field.

\section{CONCLUSION}

The results of our study demonstrate that Laparoscopic cholecystectomy is essentially a safe procedure with low morbidity and mortality rates. Guidelines for prevention of operative injury are similar to those of any operative procedure, namely adequate training and experience in humans, proper execution of appropriate techniques and accurate identification of the anatomy.

\section{REFERENCES}

[1] Roslyn JJ, Binns GS, Hughes EFX, et al. Open cholecystectomy. A contemporary analysis of 42,474 patients. Annals of Surgery 1993;218(2):129-37.

[2] Peters JH, Gibbsons GD, Innes JT, et al. Complications of laparoscopic cholecystectomy. Surg 1991;110(4):769-77.

[3] Georgiades CP, Mavromatis TN, Kourlaba GC, et al. Is inflammation a significant predictor of bile duct injury during laparoscopic cholecystectomy? Surg Endosc 2008;22(9):1959-64.

[4] Derziel DJ, Millikan KW, Economou SG, et al. Complications of laparoscopic cholecystectomy: a national survey of 4,292 hospitals and an analysis of 77,604 cases. Am J Surgery 1993;165(1):9-14.

[5] Shamiyeh A, Wayand W. Laparoscopic cholecystectomy: early and late complications and their treatment. Langenbecks Archives Surg 2004;389(3):164-71.
[6] Sawyers JL. Current status of conventional (open) cholecystectomy versus Laproscopic cholecystectomy. Annuals of Surgery 1996;223(1):1-3.

[7] Calvete J, Sabater L, Camps B, et al. Bile duct injury during laparoscopic cholecystectomy: myth or reality of learning curve? Surgical Endoscopy 2000;14(7):608-11.

[8] Rubio PA. Lessons learned from laparoscopic cholecystectomy. Int Surg 1995;80(3):197-9.

[9] Paulino-Netto A. A review of 391 selected open cholecystectomies for comparison with laparoscopic cholecystectomy. Am J Surg 1993;166(1):71-3.

[10] Cuschieri A. Minimal access surgery and the future of interventional laparoscopy. Am J Surg 1991;161(3): 404-7.

[11] Raza M, Venkata VM. Per-operative conversion of laparoscopic cholecystectomy to open surgery: prospective study at JSS teaching hospital, Karnataka, India. Int Surg J 2017;4(1):81-5.

[12] Sakpal SV, Bindra SS, Chamberlain RS. Laparoscopic cholecystectomy conversion rates two decades later. J Society of Laparoendosc Surgeons 2010;14(4):476-83.

[13] Bittner R. Laparoscopic surgery: 15 years after clinical introduction. World J Surg 2006;30(7):1190-203.

[14] Ros A, Gustafsson L, Krook H, et al. Laparoscopic cholecystectomy versus mini-laparotomy cholecystectomy: a prospective, randomized, singleblinded study. Ann Surg 2001;234(6):741-9.

[15] Sanabria JR, Gallinger S, Croxford R, et al. Risk factors in elective laparoscopic cholecystectomy for conversion to open cholecystectomy. J Am Coll Surg 1994;179(6):696-704.

[16] Peters JH, Krailadsiri W, Incarbone R, et al. Reasons for conversion from laparoscopic to open cholecystectomy in an urban teaching hospital. Am J of Surg 1994;168(6):555-9.

[17] Narwade N, Shaikh T, Jain R, et al. The study of laparoscopic cholecystectomy and its conversion to open cholecystectomy: analysis of 100 cases in Navi Mumbai, India. Int J Res Med Sci 2015;3(12):3586-90.

[18] Solheim K, Buanes T. Bile duct injury in laparoscopic cholecystectomy. Int Surg1995;80(4):361-4.

[19] Voyles CR, Petro AB, Meena AL, et al. A practical approach to laparoscopic cholecystectomy. Am J Surg 1991;161(3):365-70.

[20] Cuschieri A, Dubois F, Mouiel J, et al. The European experience with laparoscopic cholecystectomy. Am J Surg 1991;161(3):385-7.

[21] Jatzko GR, Lisborg PH, Pertl AM, et al. Multivariate comparison of complications after laproscopic cholecystectomy and open cholecystectomy. Annuals of Surg 1995;221(4):381-6.

[22] Orlando R, Russell JC, Lynch J, et al. Laparoscopic cholecystectomy. A statewide experience. Arch Surg 1993;128(5):494-9.

[23] Flowers JL, Bailey RW, Scovill WA, et al. The Baltimore experience with laparoscopic management of acute cholecystitis. Am J Surg 1991;161(3):388-92.

[24] Dubois F. Laproscopic cholecystectomy: technique and complicalions. Saudi Medical Journal 1996;17(2):12936. 